\title{
Influência dos parâmetros de corte no torneamento do ferro fundido ASTM A518 GR.3
}

\author{
Grégori Folis Dagostin ${ }^{1 *}$ (1) \\ Anderson Daleffe ${ }^{1}$ \\ Luiz Carlos de Cesaro Cavaler ${ }^{1}$
}

\begin{abstract}
Resumo
Neste artigo, buscou-se avaliar o estudo da usinabilidade de uma liga especial segundo a norma ASTM A518 GR.3 com o intuito de observar a influência dos parâmetros de corte durante a operação de torneamento externo. Através de ensaios preliminares a este estudo, um inserto de corte de modelo DNMG 150604 RK4315 foi definido para realização dos ensaios. As variáveis de entrada determinadas foram a velocidade de corte $\left(\mathrm{V}_{\mathrm{c}}\right)$ e o avanço de corte $\left(\mathrm{f}_{\mathrm{n}}\right)$, sendo fixado o valor da profundidade de corte $\left(a_{\mathrm{p}}\right)$, para todos os ensaios. Com o objetivo de determinar a vida útil do inserto nas 6 configurações de corte aplicadas, foi definido como desgaste de flanco máximo do inserto o valor de $0,3 \mathrm{~mm}$ conforme norma ISO 3685. Assim, pode-se comparar não somente os resultados de tempo de usinagem, mas também valores como taxa de remoção de material $(\mathrm{Q})$ e rugosidade média $\left(\mathrm{R}_{\mathrm{a}}\right)$ encontradas para cada configuração dos parâmetros de corte. Com os resultados encontrados pode-se então analisar a melhor condição de corte no torneamento externo para o material ASTM A518 GR.3 com a utilização do inserto DNMG 150604 RK4315, realizando a comparação dos melhores resultados obtidos quanto a vida útil da ferramenta, bem como rugosidade média $\left(R_{\mathrm{a}}\right)$ resultante e volume de material removido $\left(\mathrm{cm}^{3}\right)$. A configuração dos parâmetros de corte definida como a mais adequada neste estudo apresentou a maior vida útil, o maior volume de material removido $\left(\mathrm{cm}^{3}\right)$ e a terceira menor rugosidade média $\left(\mathrm{R}_{\mathrm{a}}\right)$ perante as 6 configurações testadas.
\end{abstract}

Palavras-chave: Usinagem; Torneamento; Parâmetros de corte; ASTM A518 GR.3.

\section{Influence of cutting parameters on ASTM A518 GR.3 alloy turning}

\begin{abstract}
In this article, we sought to evaluate the study of the machinability of a special alloy according to the ASTM A518 GR.3 standard in order to observe the influence of the cutting parameters during the external turning operation. Through preliminary tests to this study, a cutting insert of model DNMG 150604 RK4315 was defined to perform the tests. The input variables determined were the cutting speed $\left(V_{c}\right)$ and the cutting advance $\left(f_{n}\right)$, with the cutting depth $\left(a_{p}\right)$ value being fixed for all tests. In order to determine the cutting life of the insert in the 6 cutting configurations applied, the maximum flank wear of the insert was defined as $0,3 \mathrm{~mm}$ according to ISO 3685 . Thus, it is possible to compare not only the results of machining time, but also values such as material removal rate $(\mathrm{Q})$ and average roughness $\left(\mathrm{R}_{\mathrm{a}}\right)$ found for each setting of the cutting parameters. With the results found, it is then possible to analyze the best cutting condition in the external turning for the material ASTM A518 GR.3 using the insert DNMG 150604 RK4315, making the comparison of the best results obtained regarding the tool life, as well as resulting average roughness $\left(\mathrm{R}_{\mathrm{a}}\right)$ and volume of material removed $\left(\mathrm{cm}^{3}\right)$. The configuration of the cutting parameters defined as the most appropriate in this study showed the longest cutting life, the largest volume of material removed $\left(\mathrm{cm}^{3}\right)$ and the third lowest mean roughness $\left(\mathrm{R}_{\mathrm{a}}\right)$ towards the 6 tested configurations.
\end{abstract}

Keywords: Machining; Turning; Cutting parameters; ASTM A518 GR.3.

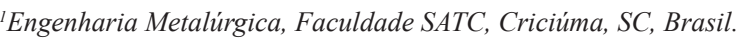

*Autor correspondente: gregorifd@hotmail.com

2176-1523 (C) 2021. Dagostin et al. Publicado pela ABM. Este é um artigo publicado em acesso aberto (Open Access) sob a licença Creative Commons Attribution, que permite uso, distribuição e reprodução em qualquer meio, sem restrições desde que o trabalho original seja corretamente citado. 


\section{Introdução}

A maioria da indústria de manufatura visa produzir um grande número de produtos em um tempo relativamente menor e, a alta demanda de produção e a alta qualidade das peças usinadas são os principais desafios da indústria de manufatura [1].

A liga ASTM A518 GR.3 a ser estudada neste artigo é amplamente utilizada na fabricação de peças para a indústria química, sendo estas peças geralmente usinadas em todo ou em grande parte do seu perfil. Uma das operações de usinagem que pode ser encontrada com maior frequência nas etapas de produção destas peças é o torneamento, sendo esta operação a escolhida para a realização do estudo de usinabilidade aqui apresentado. Sendo assim, serão descritos mais detalhadamente alguns conceitos envolvidos no estudo da usinabilidade deste material.

\subsection{Ferros fundidos alto silício}

As ligas fundidas de ferro silício, contendo aproximadamente $0,8 \% \mathrm{C}, 15 \% \mathrm{Si}, 0,7 \% \mathrm{Mn}$, geralmente apresentam o $\mathrm{Cr}$ em teores até $5,50 \% \mathrm{e}$, pertencem à família dos ferros fundidos. A estrutura é constituída por solução sólida cristalina (silício-ferrita), com carbono livre na forma de grafita lamelar finamente distribuída, Figura 1.

Estas ligas são cobertas por diversas normas internacionais, entre elas a ASTM A518 [3]. Devido à sua grande resistência à corrosão química, em um extenso campo de aplicação, estas ligas são materiais padrão na tecnologia química de ácidos em geral. Vale ressaltar a sua excelente resistência à abrasão, a qual está sempre associada à corrosão nos processos químicos industriais. As ligas de ferro silício resistem ao ataque de praticamente todas as concentrações de ácido sulfúrico em temperaturas de até $300^{\circ} \mathrm{C}$, inclusive as concentrações mais agressivas na faixa de 10-30\%. Também para o ácido nítrico concentrado e seus vapores, a resistência à corrosão deve ser elevada, sendo, portanto, materiais indispensáveis na fabricação de ácido nítrico, fertilizantes e explosivos [4].

Mesmo com o advento de novas ligas inoxidáveis, das superligas e dos materiais sintéticos resistentes à corrosão, as ligas de ferro silício mantém o seu espaço em aplicações específicas, sem outras alternativas de material à altura. Como exemplos de aplicação, pode-se citar componentes de bomba para a indústria química e componentes de torres de concentração de ácidos.

A fabricação de peças nestas ligas, porém, apresentam uma série de problemas associados com fragilidade, tendência à trincas, porosidade, usinabilidade difícil, dificuldade/ impossibilidade de soldagem, problemas estes que exigem aprimorada tecnologia em todas as etapas de fabricação para serem contornados [4]. Com uma grande quantidade de silício alternando de 12 a $18 \%$, ferros fundidos passam a ser muito resistentes à corrosão ácida. Os limites máximos e mínimos estipulados pela norma ASTM A518 GR.3 estão apresentados na Tabela 1 .

Com um conteúdo de silício de $14,5 \%$ ou mais, estes ferros fundidos apresentam uma grande resistência a banho em ácido sulfúrico $30 \%$. Ferros fundidos alto silício com $16,5 \%$ Si são resistentes a banhos de ácido sulfúrico e nítrico em quase todas as concentrações. Entretanto, devido ao seu alto conteúdo de silício, estas ligas apresentam propriedades mecânicas ruins como baixa resistência ao choque térmico e mecânico, sendo difíceis de vazar e são não usináveis [5].

Tabela 1. Composição química (\% em peso) conforme norma ASTM A518 GR.3 [3]

\begin{tabular}{ccc}
\hline \multirow{2}{*}{ ELEMENTO } & \multicolumn{2}{c}{ ASTM A518 GR.3 } \\
\cline { 2 - 3 } & \% MíN & \% MÁX \\
\hline C & 0,70 & 1,10 \\
Mn & - & 1,50 \\
Si & 14,20 & 14,75 \\
Cu & - & 0,50 \\
Cr & 3,25 & 5,00 \\
Mo & - & 0,20 \\
\hline
\end{tabular}

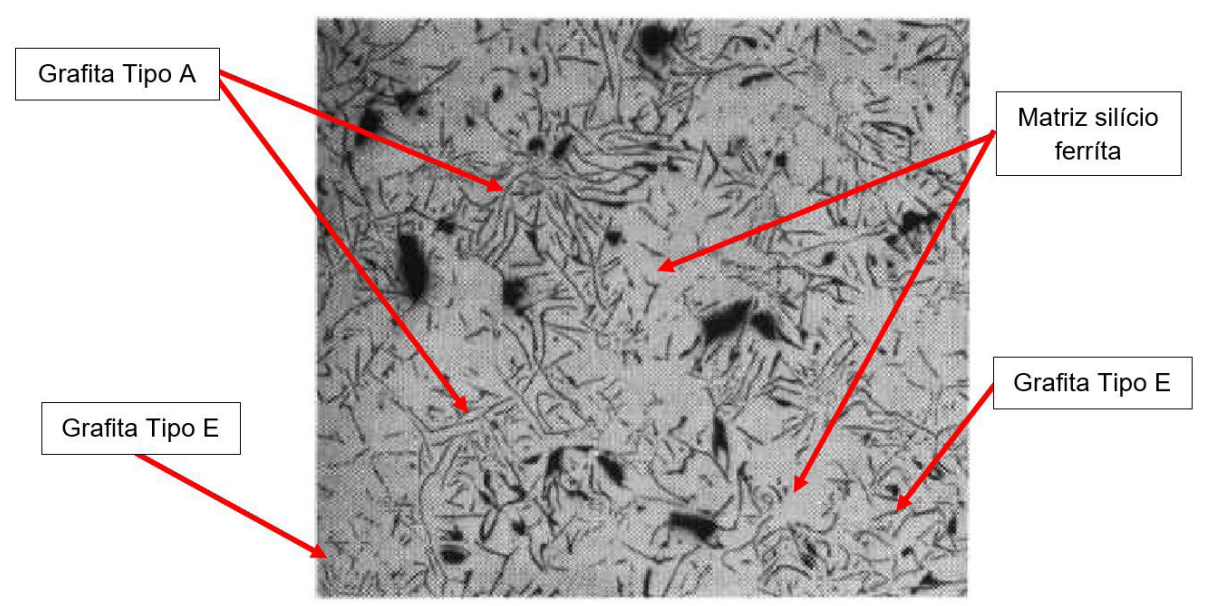

Figura 1. Ferro fundido alto silício resistente à corrosão $(0,9 \% \mathrm{C}, 14,5 \% \mathrm{Si}, 1,0 \% \mathrm{Mn}, 4,5 \% \mathrm{Cr})$ como fabricado. Microestrutura composta por flocos de grafita dos tipos A e E (regiões escuras) distribuídas em matriz sólida cristalina (silício ferrita). (HNO3 mais HF, em glicerol; X 100.) [2]. 


\subsection{Usinabilidade e o processo de torneamento}

A usinabilidade dos materiais é uma propriedade difícil de ser determinada, pois depende de diversos fatores dos processos de usinagem, ou seja: velocidade de corte $\left(\mathrm{V}_{\mathrm{c}}\right)$, avanço de corte $\left(f_{n}\right)$, profundidade de corte $\left(a_{p}\right)$ e tipos das ferramentas, das máquinas operatrizes e dos fluidos de corte. Cada material apresenta condições particulares que ditam as normas mais adequadas de usinagem [6]. Industrialmente, a avaliação mais expressiva da usinabilidade do aço ou ferro fundido se faz através do custo necessário para produzir um grupo de peças em máquina operatriz. As peças devem atender a uma avaliação de qualidade, sendo necessário que tenham tolerância dimensional, acabamento da superfície e integridade funcional. Considerados esses fatores como necessários, o custo mínimo das peças somente pode ser alcançado através de uma alta produtividade obtida com elevadas velocidades de corte e baixo desgaste das ferramentas [6].

A usinabilidade não é uma propriedade intrínseca do material, mas, sim, um resultado da interação do metal com a operação de usinagem. As condições de usinagem são estabelecidas para cada tipo de material e ferramenta. $\mathrm{O}$ avanço e a velocidade são limitados pelo calor gerado pelos atritos e pela deformação plástica do cavaco. Quanto maior a usinabilidade do material da peça e a resistência ao desgaste do material da ferramenta, maiores podem ser os avanços e as velocidades de corte. Em grande maioria dos casos, a profundidade de corte é um fator que limita o avanço e a velocidade de corte [6].

Durante o processo de usinagem, uma fricção intensa é gerada na interface peça e ferramenta, e onde a menor condutividade térmica da liga resulta em deformação plástica severa na área local da peça devido à geração excessiva de calor. Este efeito juntamente com os resultados de endurecimento do trabalho na descolagem do substrato da ferramenta leva a um acabamento de superfície deficiente, desgaste excessivo da ferramenta, maiores forças de corte, baixa produtividade e grande quantidade de consumo de energia [7]. Entendem-se, como propriedades de usinagem de um metal, aquelas que expressam o seu efeito sobre grandezas mensuráveis inerentes ao processo de usinagem. Para avaliação da usinabilidade, são, geralmente, usados quatro critérios, utilizados isoladamente ou em conjunto: vida útil da ferramenta, força de usinagem, qualidade da superfície da peça e formação de cavacos (forma e tamanho dos cavacos) [6].

\subsection{Mecanismo de desgaste no inserto de usinagem}

A qualidade da superfície do componente usinado depende do tipo de inserto de corte usado. O comportamento da inserção pode ser atribuído ao tipo de revestimento usado. Os revestimentos aumentarão as propriedades de resistência ao desgaste da ferramenta e também poderão reduzir forças de corte e temperaturas [7].
Em parâmetros de usinagem mais altos, o aumento das velocidades de corte, avanços e profundidade de corte resultam no aumento da força de corte e da rugosidade da superfície. Os parâmetros de usinagem que influenciam na força de corte e na rugosidade da superfície do componente são a velocidade de corte, avanço por rotação, profundidade de corte radial, geometria da ferramenta de corte, material de trabalho, condições de usinagem e ferramenta de corte em balanço [8].

O desgaste da ferramenta é um processo natural que se desenvolve na ferramenta de corte durante as operações de usinagem devido a cargas mecânicas, químicas e térmicas. Vários mecanismos de desgaste aparecem na zona de corte devido a esses efeitos externos, ou seja, desgaste do flanco (VB) e desgaste da cratera. Os dois tipos de desgaste considerados como critério para a vida útil da ferramenta fornecem informações previsíveis e confiáveis. O desgaste do flanco pode ser usado como critério de vida útil da primeira ferramenta [9]. O critério de vida da ferramenta é um desgaste máximo do flanco de desgaste de $300 \mu \mathrm{m}$ ou entalhe $600 \mu \mathrm{m}$, de acordo com a norma ISO 3685 [10].

No mecanismo de desgaste abrasivo, as partículas abrasivas rompidas na peça causam um efeito de atrito na área entre a ferramenta e a peça. $\mathrm{O}$ mecanismo ocorrido aciona o desenvolvimento do desgaste do flanco, que se desenvolve na superfície de folga da ferramenta de corte. A quebra do inserto pode causar um efeito catastrófico no porta-ferramenta ou na peça de trabalho. Os sinais de falha da ferramenta podem ser vistos como resultado do aumento das forças de corte e do consumo de energia, reduzindo a qualidade da superfície e a precisão dimensional. Quando a qualidade do produto é considerada o principal objetivo da fabricação, o desgaste da ferramenta desempenha um papel importante [9].

Uma boa compreensão do processo de remoção de material no corte de metal é essencial na seleção do material da ferramenta e design, e também na garantia de precisão dimensional consistente e integridade da superfície do produto acabado. $\mathrm{O}$ atrito de corte do metal influencia o poder de corte, a qualidade da superfície usinada, a vida útil da ferramenta e o custo de usinagem. Quando o desgaste da ferramenta atinge um determinado valor, aumentando a força de corte, vibração e temperatura de corte, isso faz com que a superfície fique deteriorada e ocorra um erro de dimensão maior que a tolerância [11].

Para estabelecer uma relação funcional adequada entre as respostas (como a rugosidade da superfície, força de corte, vida / desgaste da ferramenta) e os parâmetros de corte (velocidade de corte, avanço, profundidade de corte, raio de quina, tempo de corte, etc.), um grande número de testes é necessário, exigindo um conjunto separado de testes para cada combinação de corte, ferramenta e material da peça de trabalho [11].

O acabamento da superfície no torneamento é influenciado em quantidades variadas por vários fatores, como a velocidade de corte, velocidade de avanço, 
profundidade de corte, características do material, geometria da ferramenta, deflexão da peça, estabilidade e rigidez da máquina-ferramenta - ferramenta de corte - sistema de peça, aresta montada, fluido de corte, etc [11].

\subsection{Rugosidade}

As operações de corte de metal são generalizadas na indústria de transformação e a previsão e / ou o controle de parâmetros de usinabilidade sempre atraem interesse. Um parâmetro básico de usinabilidade é a textura da superfície, pois está intimamente associada à qualidade, confiabilidade e desempenho funcional dos componentes [12].

Na prática industrial comum, a rugosidade da superfície é avaliada principalmente pelos parâmetros de rugosidade $\mathrm{R}_{\mathrm{a}}$ (média) e $\mathrm{R}_{\mathrm{t}}$ (máxima). No entanto, deve-se notar que os parâmetros acima mencionados, por si só, não fornecem informações sobre a forma do perfil. Características como inclinação e curvatura das asperezas da superfície, vazio ou plenitude do perfil, a distribuição do material do perfil em várias alturas é registrada na forma do perfil. Os aspectos tribológicos essenciais (por exemplo, atrito, desgaste, estado de lubrificação) são altamente dependentes da forma do perfil.

As forças de corte são o resultado de condições extremas experimentadas durante o contato da peça e da ferramenta. A interação dos parâmetros de corte pode estar diretamente relacionada ao desgaste da ferramenta e, nos piores casos, à falha da ferramenta. Consequentemente, o desgaste da ferramenta e as forças de corte estão relacionadas entre si.

As rugosidades da superfície, bem como o monitoramento da força de corte, são essenciais para determinar o desempenho dos processos de usinagem e expandir a vida útil da ferramenta [12].

A rugosidade aumenta com o aumento do avanço e diminui com o aumento do raio de quina. Com relação à velocidade de corte, a rugosidade inicialmente tende a aumentar com o aumento da velocidade de corte, diminuindo após uma certa velocidade. Isso se deve à formação de gume postiço, que pode ocorrer a pequenas velocidades de corte, fator que desaparece com o emprego de velocidades de corte mais altas. A profundidade de corte praticamente não tem influência sobre a qualidade superficial, quando a profundidade for superior a um valor mínimo. Dos ângulos da ferramenta, o ângulo de saída e o ângulo de posição têm a maior influência sobre a qualidade superficial. Com o aumento positivo do ângulo de saída a rugosidade diminuí. A diminuição do ângulo de posição leva a um aumento da força passiva e, em decorrência, aumenta a possibilidade de vibrações regenerativas, que levam a uma piora da qualidade superficial. Também o desgaste da ferramenta tem influência sobre a qualidade superficial da peça [6].

\section{Materiais e métodos}

Nesta etapa serão apresentados os materiais e procedimentos utilizados para o estudo de usinabilidade da liga ASTM A518 GR.3 detalhando as principais etapas do processo experimental.

\subsection{Processo de obtenção dos corpos de prova}

A geometria dos corpos de prova para realização deste estudo foi definida através da análise de um dos produtos com alto consumo pela indústria química, fabricados com a liga ASTM A518 GR.3 e posteriormente submetidos ao processo de torneamento externo. Os mesmos foram fabricados através do processo de fundição por gravidade em moldes de areia produzidos pelo processo de moldagem fenólico uretânica (PEP-SET).

Os corpos de prova foram desmoldados e submetidos ao tratamento térmico de recozimento proveniente do processo de fabricação desta liga. Após o resfriamento, os mesmos foram submetidos ao processo de acabamento e inspeção da qualidade do fundido, onde foram realizados ensaios destrutivos, tais como o ensaio de dureza Brinell e também ensaios não destrutivos como a inspeção por líquido penetrante. Estando o material bruto aprovado, neste momento os mesmos foram liberados para a etapa de usinagem. A geometria e dimensões principais dos corpos de prova já preparados podem ser avaliados na Figura 2.

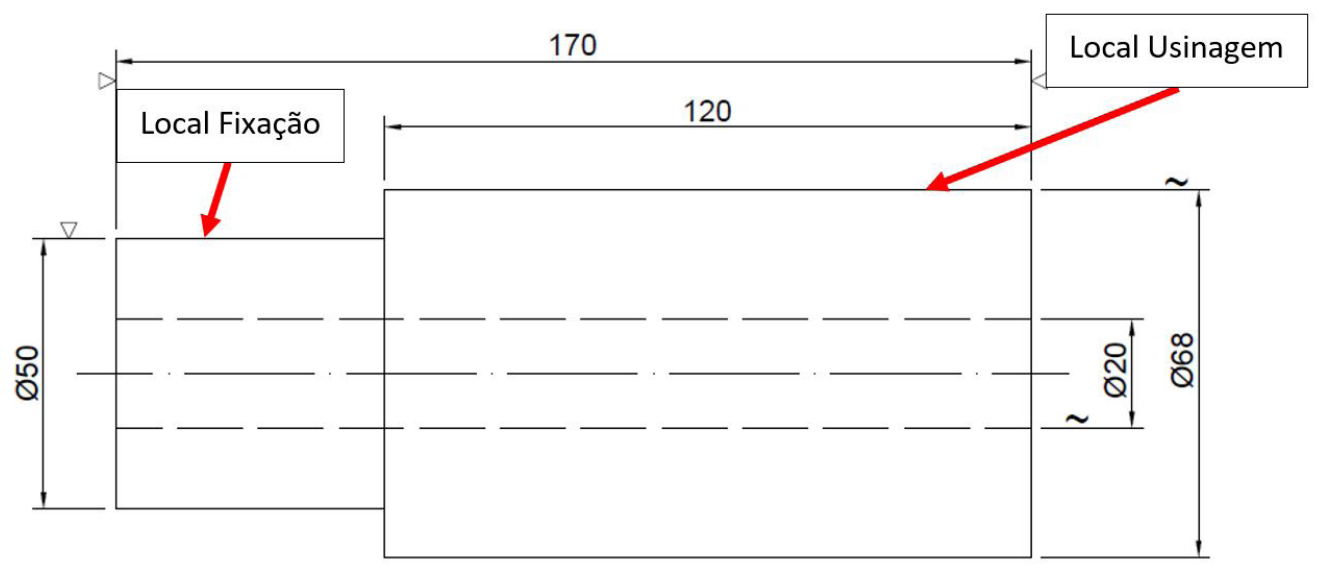

Figura 2. Dimensões do corpo de prova preparado para os ensaios de usinabilidade. Todas as medidas em mm. 
Já na usinagem, os corpos de prova foram submetidos a uma etapa de preparação antes dos ensaios principais. Nesta etapa, o corpo de prova bruto é preparado para realizar a fixação do mesmo em torno $\mathrm{CNC}$, sendo este processo realizado em torno convencional e não fazendo parte do escopo deste estudo.

\subsection{Equipamento de usinagem}

Devidamente preparados, os corpos de prova foram encaminhados ao laboratório de usinagem $\mathrm{CNC}$ onde os ensaios de usinabilidade foram realizados. $\mathrm{O}$ equipamento utilizado para os ensaios de usinabilidade foi um torno CNC modelo CENTUR 30S da marca ROMI com comando numérico modelo Mach 9. A fixação do corpo de prova no torno se deu por meio de uma placa de 3 castanhas acionada por sistema pneumático, onde a pressão de trabalho utilizada foi de 10 bar.

O sistema de fixação do suporte ferramenta no torno $\mathrm{CNC}$ é do tipo porta ferramentas com troca manual. Neste sistema a fixação da ferramenta é realizada através de um porta-ferramentas, onde inicialmente a ferramenta é fixada, sendo na sequência fixada na torre do torno pelo processo de troca manual. A Figura 3 apresenta a forma de fixação do corpo de prova e da ferramenta de corpo no torno CNC.

O motivo de realizar os ensaios de usinabilidade deste artigo em um torno $\mathrm{CNC}$ vai de encontro com o objetivo de reduzir ao máximo as variáveis que podem estar envolvidas em um processo convencional.

\subsection{Inserto de corte na usinagem}

Uma série de testes preliminares foram realizados anteriormente a este estudo, todos direcionados ao torneamento externo. Cerca de 8 insertos de diferentes fabricantes, geometrias e características foram testados e comparados. Os insertos foram submetidos a testes onde as condições de corte tais como, avanço, profundida e velocidade de corte puderam ser comparados.

O inserto que se destacou entre os avaliados foi o inserto DNMG 150604 RK4315 (fabricante SANDVIK ®) [13], sendo este o escolhido para a realização do estudo de usinabilidade apresentado neste artigo. $\mathrm{O}$ inserto escolhido possui código de formato $\mathrm{D}$, raio de quina de $0,4 \mathrm{~mm}$, cobertura CVD $\mathrm{Ti}(\mathrm{C}, \mathrm{N})+\mathrm{Al} 2 \mathrm{O} 3+\mathrm{TiN}$ e ângulo de folga igual a zero.

O suporte utilizado para fixação deste inserto no torno foi o de modelo DDJNR2020-K15, do mesmo fabricante, SANDVIK ${ }^{\circledR}$. O inserto e seus parâmetros de corte intermediários indicados pelo fabricante para a classe de material K (Classificação de materiais nível 1 - TMC1ISO) estão apresentados na Figura 4.

\subsection{Definição dos parâmetros de corte}

Visto que o material em estudo neste artigo não se trata de um ferro fundido cinzento comum (Classe K), mas sim de um ferro fundido com alto percentual (em peso) de silício e com base em alguns parâmetros levantados nos testes preliminares realizados, pode-se determinar alguns limitantes para os parâmetros de corte a serem aplicados neste estudo. Um destes limitantes foi a profundidade de corte $\left(\mathrm{a}_{\mathrm{p}}\right)$. Em todos os insertos avaliados, a máxima profundidade de corte aplicada sem que ocorressem problemas foi de $0,5 \mathrm{~mm}$. Para valores acima deste, apresentava-se a ocorrência de lascamento na região de corte do corpo de prova. Sendo assim, o valor de $0,5 \mathrm{~mm}$ foi determinado como limite máximo de profundidade de corte $\left(a_{\mathrm{p}}\right)$ para este estudo.

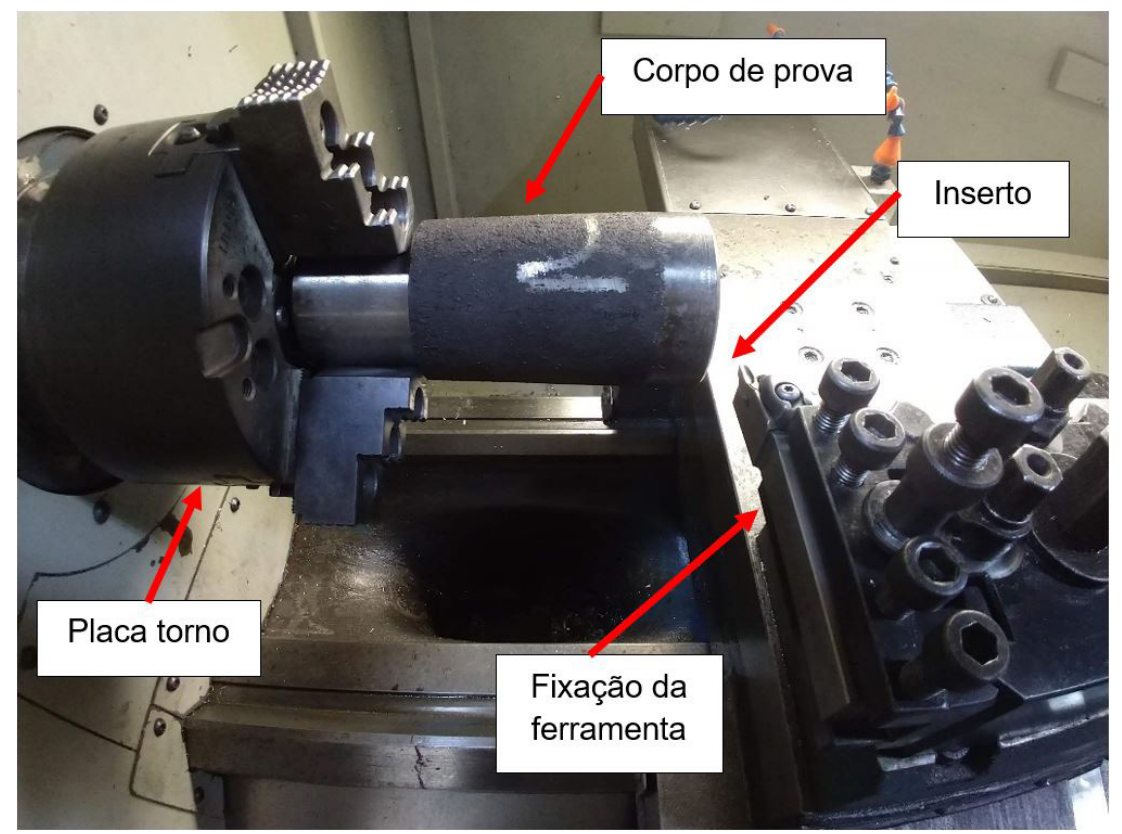

Figura 3. Sistema de fixação do corpo de prova e da ferramenta de corte no torno CNC. 


\begin{tabular}{c|c}
\hline PARÂMETRO & VALOR \\
\hline $\mathrm{RE}$ & $0,4 \mathrm{~mm}$ \\
\hline $\mathrm{S}$ & $6,35 \mathrm{~mm}$ \\
\hline $\mathrm{LE}$ & $15,1 \mathrm{~mm}$ \\
\hline Sentido de corte & Direito \\
\hline Ângulo de folga & $0 \mathrm{deg}$ \\
\hline Vida útil estimada pelo \\
fabricante
\end{tabular}

Figura 4. Parâmetros de corte e informações de geometria para o inserto DNMG 150604 RK4315 Classe de materiais K.

Nota: $\mathrm{RE}=$ Raio de canto; $\mathrm{S}=$ Espessura do Inserto; $\mathrm{LE}=$ Comprimento efetivo da aresta de corte.

Quanto ao avanço por rotação $\left(\mathrm{f}_{\mathrm{n}}\right)$, para valores acima de $0,25 \mathrm{~mm} /$ rot todos os 8 insertos testados apresentaram problemas de lascamento da região de usinagem, desgaste praticamente que instantâneo e/ou colapso do inserto de corte nos primeiros segundos de usinagem. Com esta limitação, não se pode neste momento optar por avanços maiores de $0,2 \mathrm{~mm} /$ rot.

Já para a velocidade de corte $\left(\mathrm{V}_{\mathrm{c}}\right)$, valores muito abaixo do estabelecido na Figura 4 foram utilizados. Durante os testes preliminares, as velocidades de corte dos 8 insertos testados apresentaram-se todos sempre abaixo de $100 \mathrm{~m} / \mathrm{min}$. Para o inserto escolhido não foi diferente, porém foi o inserto que se destacou nos testes preliminares quanto a velocidade de corte.

Desta forma, a velocidade de corte de $50 \mathrm{~m} / \mathrm{min}$ foi determinada como o valor intermediário a ser utilizado nos ensaios de usinabilidade. Com estas limitações e com base nos testes preliminares, pode-se então definir os parâmetros de corte intermediários para serem aplicados aos testes de usinabilidade com o inserto DNMG 150604 RK4315. $\mathrm{Na}$ Tabela 2 estão apresentadas as variáveis de entrada para os ensaios.

Foram definidas como variáveis de entrada os parâmetros de velocidade de corte e de avanço, tomando como fixa a profundida de corte aplicada a todos os ensaios. Para a velocidade de corte foram estipulados três níveis de aplicação, o intermediário, um acima e outra abaixo deste valor intermediário. Já para o avanço de corte foram estipulados dois níveis de trabalho e a profundidade de corte $\left(\mathrm{a}_{\mathrm{p}}\right)$ ficou fixada em $0,5 \mathrm{~mm}$. A Tabela 3 apresenta as 6 configurações planejadas para os ensaios de usinabilidade.

Com esta configuração, o planejamento dos ensaios pode ser elaborado. Um total de 6 configurações foram planejadas, sendo considerada a repetição de cada umas das configurações, totalizando assim 12 ensaios.
Tabela 2. Variáveis de entrada para os ensaios de usinabilidade

\begin{tabular}{ccc}
\hline $\mathbf{V}_{\mathbf{C}}(\mathbf{m} / \mathbf{m i n})$ & $\mathbf{f}_{\mathbf{n}}(\mathbf{m m} / \mathbf{r o t})$ & $\mathbf{a}_{\mathbf{p}}(\mathbf{m m})$ \\
\hline 40,0 & 0,15 & 0,5 \\
50,0 & 0,20 & - \\
73,5 & - & - \\
\hline
\end{tabular}

Tabela 3. Planejamento das configurações dos parâmetros de usinagem para os ensaios de usinabilidade

\begin{tabular}{cccc}
\hline $\begin{array}{c}\text { Código da } \\
\text { Configuração }\end{array}$ & $\mathbf{V}_{\mathbf{c}}(\mathbf{m} / \mathbf{m i n})$ & $\mathbf{f}_{\mathbf{n}}(\mathbf{m m} / \mathbf{r o t})$ & $\mathbf{a}_{\mathbf{p}}(\mathbf{m m})$ \\
\hline Vc40fn0,15 & 40,0 & 0,15 & 0,5 \\
Vc40fn0,20 & 40,0 & 0,20 & 0,5 \\
Vc50fn0,15 & 50,0 & 0,15 & 0,5 \\
Vc50fn0,20 & 50,0 & 0,20 & 0,5 \\
Vc73fn0,15 & 73,5 & 0,15 & 0,5 \\
Vc73fn0,20 & 73,5 & 0,20 & 0,5 \\
\hline
\end{tabular}

\subsection{Análise das variáveis de saída}

Determinadas as variáveis de entrada, buscou-se então estipular quais as variáveis de saída que seriam mensuradas durante a realização dos ensaios. Dentre as diversas possibilidade de respostas para avaliação de um ensaio de usinabilidade, o tempo de vida útil de corte e a rugosidade superficial do corpo de prova foram os escolhidos para representarem os resultados destes ensaios de usinabilidade, visando obter melhores tempos de usinagem, uma maior vida útil da ferramenta e uma faixa de rugosidade que venha atender a especificação dos produtos fabricados por torneamento externo para esta liga em questão. Os recursos utilizados para esta avaliação do desgaste do inserto foram: um microscópio digital USB com aumento de até 1000x, devidamente calibrado com uma precisão de medição de $0,01 \mathrm{~mm}$, um notebook no qual o microscópio digital estava conectado e o software CoolingTech ${ }^{\circledR}$ para captura das 
imagens da lupa. A Figura 5 mostra o equipamento utilizado para a avaliação do desgaste do inserto.

O tempo máximo de usinagem do inserto foi determinado conforme norma ISO 3685, critério de vida da ferramenta que estipula um desgaste máximo do flanco de $300 \mu \mathrm{m}$ ou entalhe de $600 \mu \mathrm{m}$ [14]. Para análise do desgaste da ferramenta, foram utilizados alguns recursos instalados ao lado do torno $\mathrm{CNC}$ durante os ensaios demonstrados na Figura 5.

A rugosidade foi avaliada a cada término de passe, no sentido longitudinal do corpo de prova, sendo esta realizada sempre em 3 regiões (1, 2 e 3$)$, demarcadas pela posição das castanhas da placa pneumática do torno CNC. Foi utilizado um rugosímetro modelo SJ-310 da

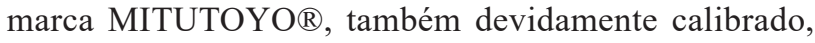
mostrado Figura 6.

A metodologia dos ensaios se deu da seguinte forma, a cada passe o inserto de corte foi removido do suporte modelo DDJNR2020-K15 e levado até a bancada próxima ao torno onde a lupa estava instalada.

A avaliação do desgaste no inserto foi realizada através da medição do desgaste ocorrido na aresta de corte conforme procedimento apresentado na Figura 5 e também a medição de rugosidade no corpo de prova, que por sua vez foi realizada com o posicionamento do rugosímetro sobre a região de usinagem no sentido longitudinal com a peça fixada na placa.

Caso o desgaste de flanco (VB) do inserto estivesse abaixo dos valores estipulados pela norma ISO 3685, o inserto seria medido e fixado novamente ao suporte e um novo passe iniciado. Se o desgaste encontrado estivesse igual ou acima do valor estipulado pela norma ISO 3685 , considerava-se o término do ensaio.

A cada passe o tempo de corte (em minutos) foi registrado e assim, pode-se então ser determinado a vida

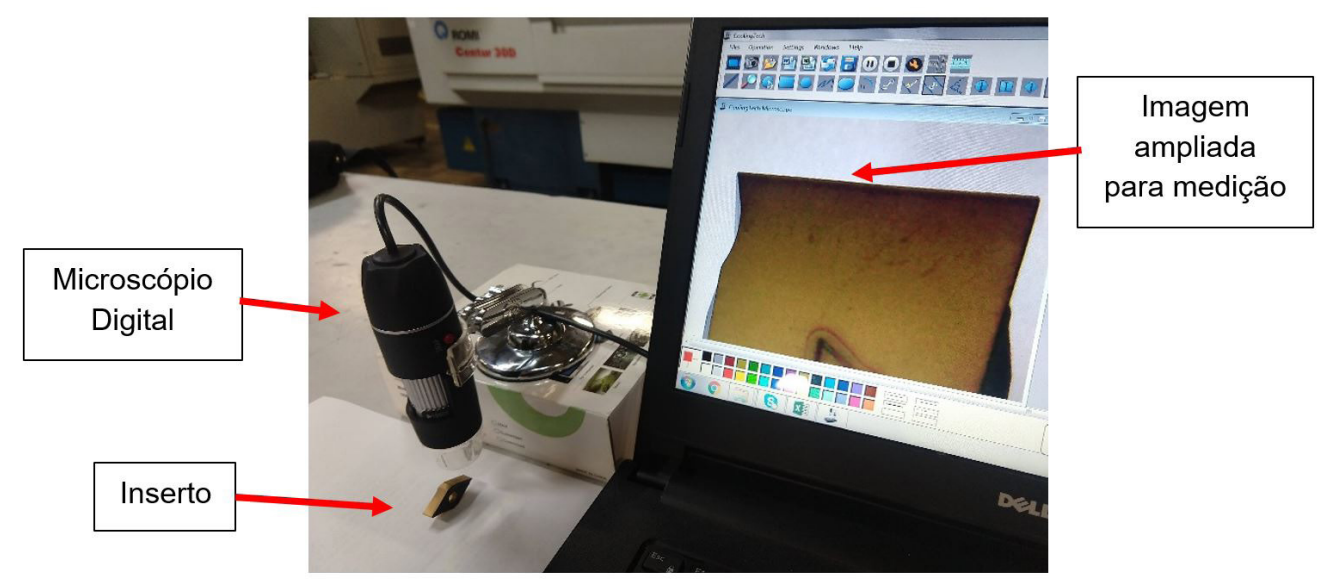

Figura 5. Microscópio digital USB, aumento de até 1000x. Fonte: Autor, 2019.

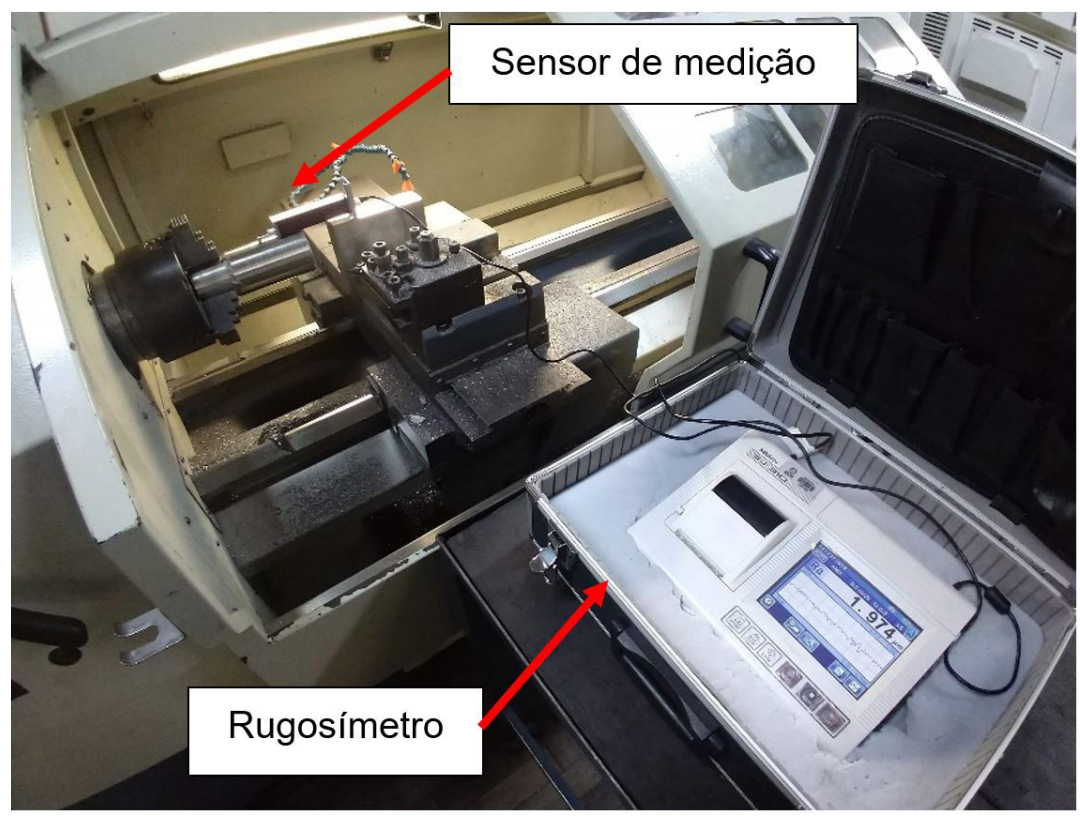

Figura 6. Rugosímetro Portátil Surftest SJ-310, Fabricante MITUTOYO®. 
útil (em minutos) deste inserto para as 6 configurações de corte aplicadas. Ao concluir o ensaio de uma determinada configuração, um novo gume do inserto foi posicionada e um novo ensaio iniciado. As repetições dos ensaios foram realizadas após o término de todas as 6 configurações.

\section{Resultados}

Com a análise da composição química e dureza dos corpos de prova, junto ao acompanhamento das 6 configurações de corte aplicadas aos ensaios de usinabilidade e suas repetições, pode-se reunir os resultados e apresentá-los para uma melhor análise do estudo de usinabilidade no torneamento externo da liga ASTM A518 GR.3 utilizando o inserto DMNG 150604 RK4315.

\subsection{Propriedades físicas e químicas obtidas nos corpos de prova}

Os corpos de prova foram caracterizados afim de se confirmar se a composição química resultante dos mesmos se encontrava dentro dos limites estabelecidos pela norma ASTM A518 GR.3. O resultado da composição química da corrida de fabricação dos corpos de prova segue apresentado na Tabela 4.

A dureza dos corpos de prova também foi avaliada com o objetivo de verificar a homogeneidade entre os

Tabela 4. Composição química da corrida de fabricação dos corpos de prova

\begin{tabular}{cccccc}
\hline \multirow{2}{*}{ Elemento } & Amostra & & \multicolumn{2}{c}{ ASTM A518 GR.3 } \\
\cline { 2 - 3 } \cline { 5 - 5 } & \% (Peso) & & \% (Peso) mín & \% (Peso) máx \\
\hline $\mathrm{C}$ & 0,84 & & 0,70 & - & 1,10 \\
$\mathrm{Mn}$ & 0,55 & & - & 1,50 \\
$\mathrm{Si}$ & 14,72 & & 14,20 & 14,75 \\
$\mathrm{Cu}$ & 0,48 & & - & 0,50 \\
$\mathrm{Cr}$ & 4,95 & & 3,25 & 5,00 \\
$\mathrm{Mo}$ & 0,017 & & - & 0,20 \\
\hline
\end{tabular}

mesmos. O método utilizado para a medição de dureza dos corpos de prova foi o Brinell. Os valores das 6 medições de dureza apresentaram o mesmo resultado de 375 HB. Visto ser esperado pela norma uma dureza próxima a $350 \mathrm{HB}$ sem um limite máximo ou mínimo determinado, os corpos de prova foram considerados aprovados apresentando uma homogeneidade entre si.

Ensaios não destrutivos de líquido penetrante também foram realizados afim de identificar a integridade superficial do fundido, buscando isentar a peça de defeitos como trincas, visto ser um problema comumente encontrado neste tipo de material devido a sua fragilidade.

\subsection{Avaliação de desgaste do inserto}

Como descrito na etapa de materiais e métodos, o inserto foi submetido a passes de torneamento externo em cada corpo de prova, sendo o tempo de cada passe registrado. Após cada passe, o inserto foi removido do seu devido suporte e realizado a análise de desgaste VB no gume de corte do inserto.

A vida útil do inserto foi definida conforme norma ISO 3685. Ao realizar a análise do inserto, estando ele com um desgaste menor que o estipulado pela norma, um novo passe com as mesmas configurações no mesmo corpo de prova foi aplicado. Desde modo, o tempo de vida útil total foi definido com o somatório dos tempos de cada passe realizado, com suas respectivas configurações de corte e seu corpo e prova até que o desgaste do inserto fosse igual ou superior ao estipulado pela norma.

Na Figura 7, pode-se comparar o estado da aresta de corte de um inserto novo sem desgaste (a) com um outro inserto apresentando desgaste de flanco máximo VB na aresta de corte (b). O inserto com desgaste apresentado foi utilizado para o teste de usinabilidade com as configurações de corte Vc40fn0,20 no final de sua vida útil.

Nas Figuras 8 e 9, pode-se acompanhar a relação de desgaste máximo do flanco VB com as configurações de velocidades de corte e avanços utilizados nos ensaios,

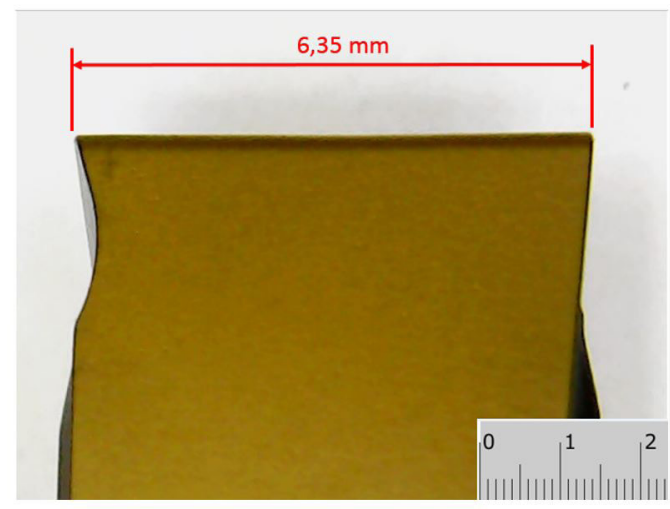

(a)

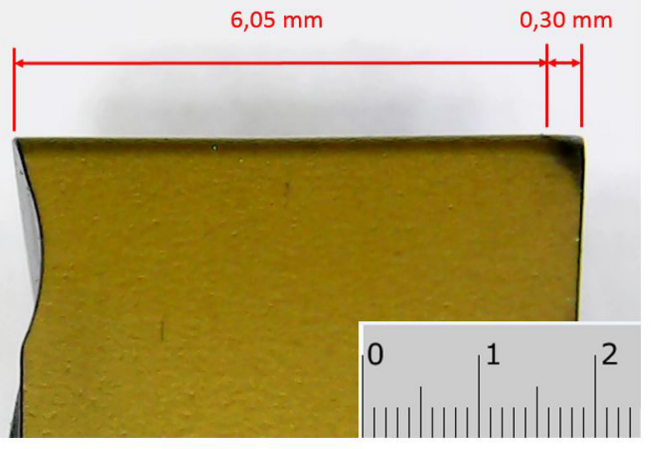

(b)

Figura 7. (a) Inserto novo sem desgaste; (b) Inserto apresentando desgaste máximo estipulado pela norma ISO 3685 (0,3 mm). 


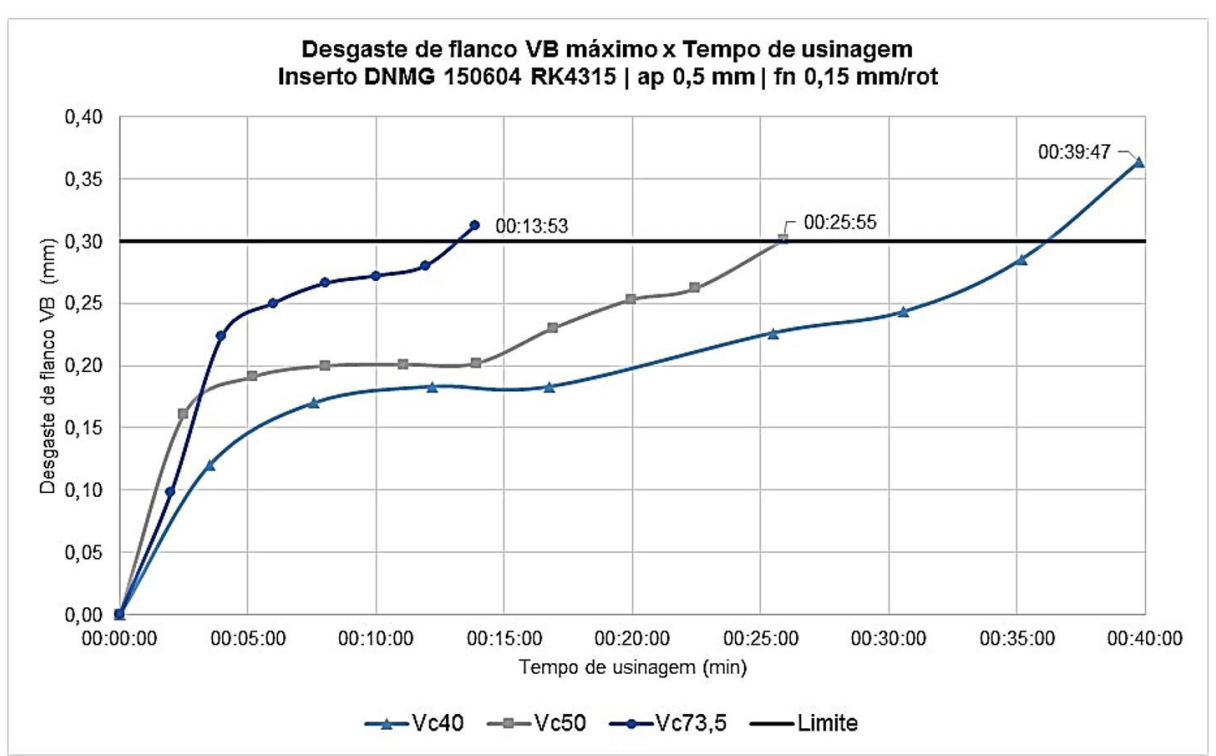

Figura 8. Comportamento do desgaste do inserto em relação a vida útil para diferentes velocidades de corte com avanço de $0,15 \mathrm{~mm} / \mathrm{rot}$.

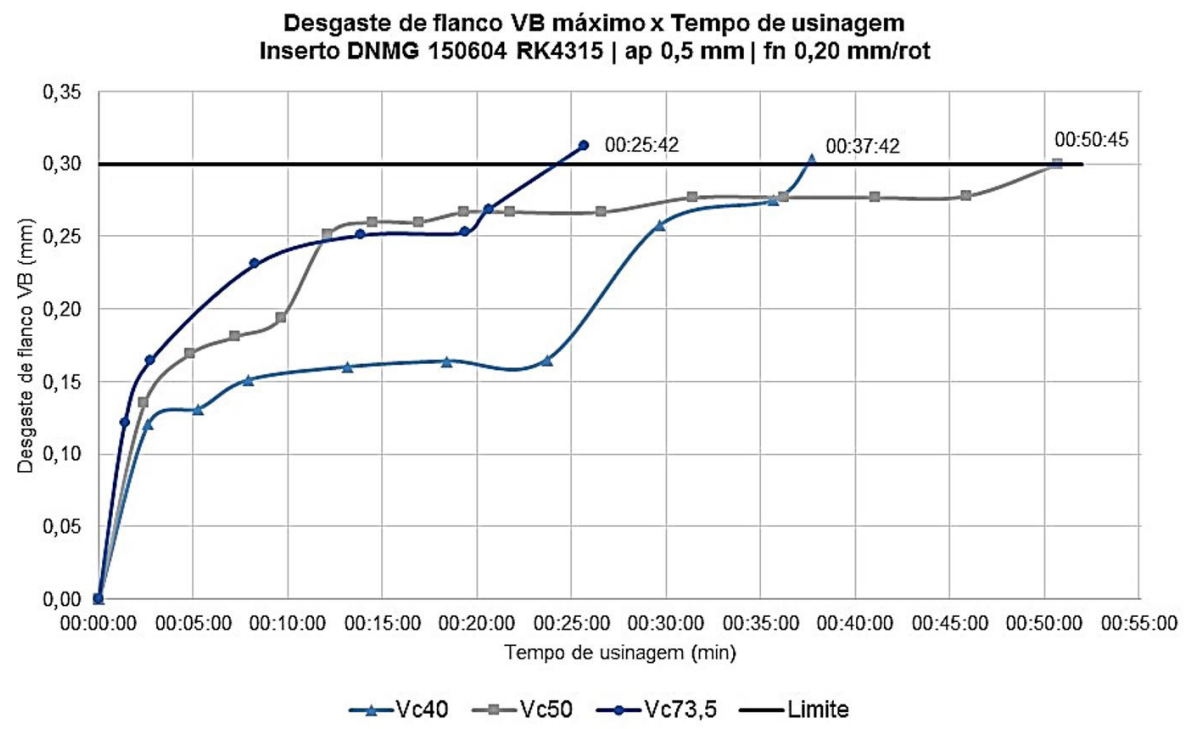

Figura 9. Comportamento do desgaste do inserto em relação a vida útil para diferentes velocidades de corte com avanço de $0,20 \mathrm{~mm} /$ rot.

lembrando que para todas as configurações a profundidade de corte $\left(a_{p}\right)$ foi mantida em $0,5 \mathrm{~mm}$.

O tempo máximo de usinagem foi definido através da verificação do limite de desgaste no flanco VB máximo conforme norma ISO 3685. Ao término de cada passe, o desgaste na aresta de corte foi verificado, caso o mesmo atingisse o valor igual ou superior a $0,3 \mathrm{~mm}$ o ensaio desta determinada configuração de corte estaria concluído, tendo assim encontrado o tempo máximo de usinagem, ou seja, a vida útil do inserto para aqueles parâmetros de corte utilizados.

Além do tempo máximo de usinagem, com a ajuda das Figuras 8 e 9 pode-se acompanhar o comportamento do desgaste do flanco durante a passagem do tempo para cada configuração de corte.

\subsection{Tempo de usinagem máximo em relação ao avanço e velocidade de corte}

Seguindo o método de verificação anteriormente demonstrado e com todos as 6 configurações de corte ensaiadas, um dos objetivos deste trabalho foi determinar a vida útil do inserto em estudo para cada uma das configurações de corte utilizadas.

A Figura 10 apresenta o comportamento da vida útil do inserto perante estas combinações. É possível de se identificar a tendência da redução da vida útil do inserto com o aumento da velocidade de corte para as configurações que utilizaram avanço de $0,15 \mathrm{~mm} /$ rot. Já para a segunda configuração de avanço aplicada, ou seja, $0,20 \mathrm{~mm} / \mathrm{rot}$, a velocidade de corte intermediária de $50 \mathrm{~mm} / \mathrm{min}$ apresentou a maior vida útil deste conjunto de ensaios. 


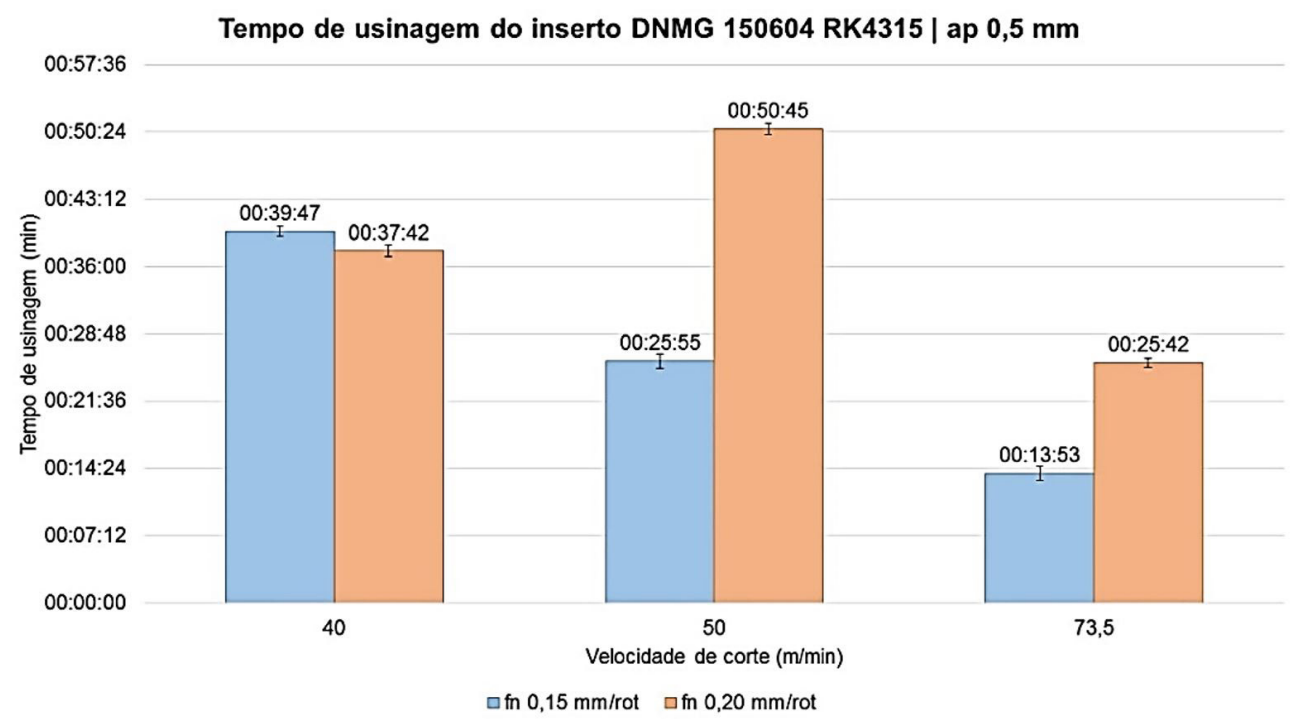

Figura 10. Tempo de usinagem máximo do inserto em relação as configurações de corte utilizadas.

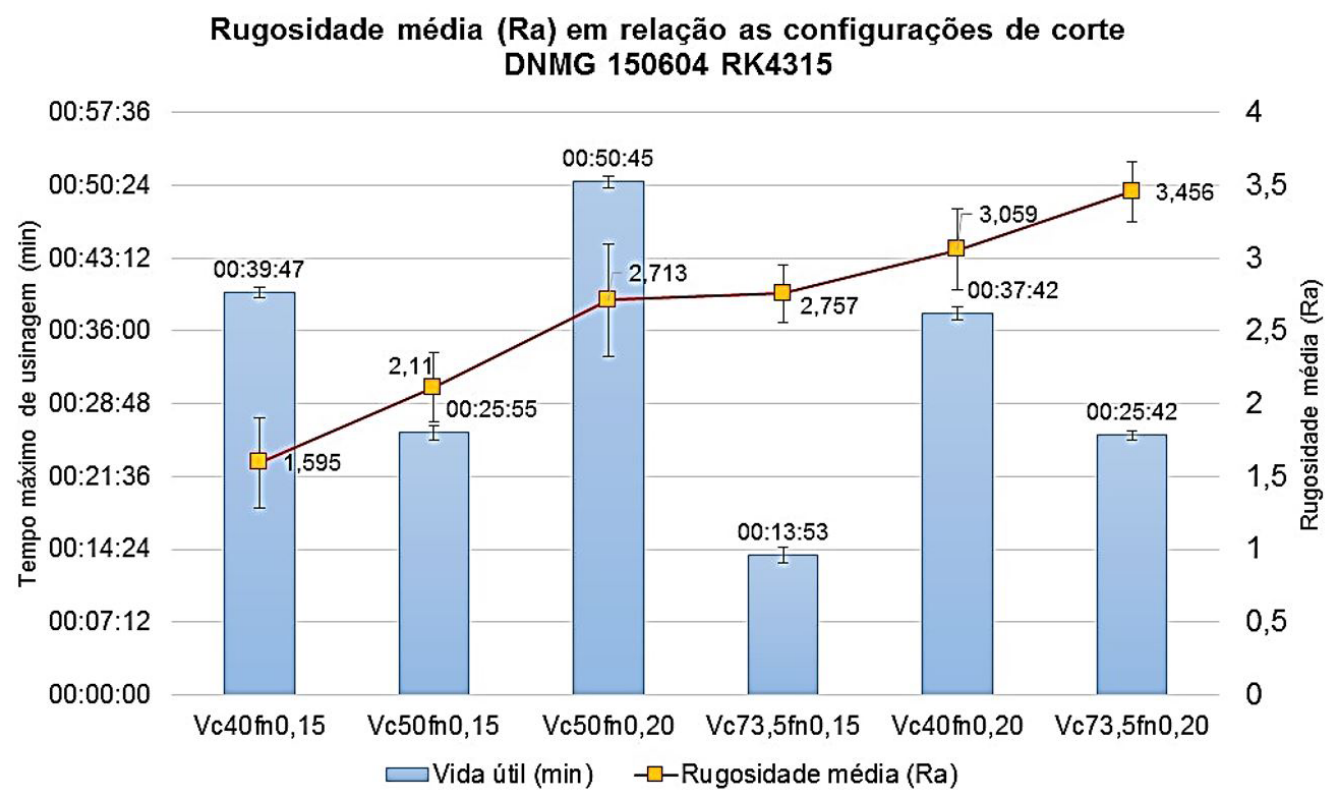

Figura 11. Rugosidades médias $\mathrm{R}_{\mathrm{a}}$ encontradas para cada configuração de corte aplicada.

Com a análise destes resultados, pode-se afirmar que o inserto DMNG 150604 RK4315 apresentou maior vida útil com a configuração de corte Vc50fn 0,20 , ou seja, Velocidade de corte $50 \mathrm{~mm} / \mathrm{min}$ e avanço $0,20 \mathrm{~mm} /$ rot. A menor vida útil pode ser encontrada na configuração Vc73fn 0,15 , velocidade de corte $73,5 \mathrm{~mm} / \mathrm{min}$ e avanço $0,15 \mathrm{~mm} /$ rot respectivamente.

Com a análise destes resultados, pode-se afirmar que o inserto DMNG 150604 RK4315 apresentou maior vida útil com a configuração de corte $\mathrm{Vc5} 5 \mathrm{fn} 0,20$, ou seja, velocidade de corte $\left(\mathrm{V}_{\mathrm{c}}\right)$ de $50 \mathrm{~mm} / \mathrm{min}$ e avanço $\left(\mathrm{f}_{\mathrm{n}}\right) 0,20 \mathrm{~mm} / \mathrm{rot}$. A menor vida útil pode ser encontrada na configuração Vc73fn0,15, com velocidade de corte $\left(V_{c}\right) 73,5 \mathrm{~mm} / \mathrm{min}$ e avanço $\left(f_{n}\right) 0,15 \mathrm{~mm} /$ rot respectivamente.

\subsection{Rugosidade média $\left(R_{\mathrm{a}}\right)$ em relação ao avanço e velocidade de corte}

A rugosidade média aritmética $\left(\mathrm{R}_{\mathrm{a}}\right)$ dos corpos de prova foi calculada através das medições realizadas durante os passes de usinagem executados em cada uma das configurações de corte aplicadas, sendo considerada a última medição da configuração quando o desgaste do inserto exceder o limite de $0,3 \mathrm{~mm}$, o desgaste de flanco máximo VB considerado para este estudo. Os resultados destas medições podem ser avaliados na Figura 11, apresentados na ordem crescente para os valores de rugosidade média $\left(\mathrm{R}_{\mathrm{a}}\right)$.

As rugosidades médias $\left(R_{a}\right)$ encontradas para as 6 configurações de corte aplicadas apresentaram valores entre 
$1,6 \mu \mathrm{m}$ com a velocidade mais baixa de $40 \mathrm{~m} / \mathrm{min}$ e chegando até $3,5 \mu \mathrm{m}$ com o aumento da velocidade de corte para $73,5 \mathrm{~m} / \mathrm{min}$.

Pode-se perceber uma relação direta entre o aumento da rugosidade média $\left(\mathrm{R}_{\mathrm{a}}\right)$ com o aumento da velocidade de corte e do avanço para os experimentos, exceto para a configuração de corte Vc40fn0,20.

Pela relação lógica apresentada, esta configuração deveria apresentar a segunda menor rugosidade média Ra. $O$ resultado encontrado mostra que para esta configuração a relação anteriormente encontrada não se fez presente, onde ela apresentou uma rugosidade considerada como a segunda maior de todas 6 configurações.

\subsection{Taxa de remoção de material (Q) em relação ao avanço e velocidade de corte}

Nesta análise, foram comparados os valores das taxas de remoção entre os 6 ensaios realizados. A taxa de remoção de material na usinagem é calculada em função da velocidade de corte, avanço e profundidade de corte. Visto que a profundidade de corte foi mantida para todos os ensaios realizados, os parâmetros de influência neste momento foram o avanço e a velocidade de corte. Os valores das taxas de remoção estão apresentados na Figura 12.

A maior taxa de remoção foi obtida com a configuração Vc73fn 0,20 , ou seja, os valores máximos de avanço $(0,2 \mathrm{~mm} /$ rot $)$ e de velocidade de corte $(73,5 \mathrm{~m} / \mathrm{min})$ utilizados, porém esta configuração foi a que apresentou o segundo menor tempo de usinagem do inserto, um pouco menos de 26 minutos.

\subsection{Volume de material removido (T) em relação ao avanço e velocidade de corte}

Após calculada a taxa de remoção $(\mathrm{Q})$ para cada das 6 configurações de corte realizadas, pode-se obter os valores de volume de material removido $\left(\mathrm{em}^{3} \mathrm{~cm}^{3}\right)$ através do tempo máximo de corte. Os resultados encontrados estão apresentados na Figura 13 de forma crescente quanto ao volume de material removido.

O maior volume de material removido foi obtido na configuração $\mathrm{Vc} 50 \mathrm{fn} 0,20$, chegando a $0,176 \mathrm{~cm}^{3}$ removidos durante todo o ensaio. Pode-se perceber que esta configuração foi a que apresentou a terceira maior taxa de remoção (Q), cerca de $5 \mathrm{~cm}^{3} / \mathrm{min}$. Neste caso, o maior tempo de usinagem obtido neste ensaio contribuiu para este maior resultado de volume de material removido.

\subsection{Análise geral dos resultados}

Com base nos resultados das análises anteriormente apresentadas, a Tabela 5 foi elaborada apresentando assim as variáveis de entrada para cada configuração de ensaio realizado e seus respectivos resultados obtidos. Todos os ensaios foram realizados com o inserto DNMG 150604 RK4315 fixado ao suporte DDJNR2020-K15 e com profundidade de corte $\left(a_{\mathrm{p}}\right)$ de $0,5 \mathrm{~mm}$.

Para uma melhor análise dos resultados, os dados da Tabela 5 foram plotados em um gráfico apresentado na Figura 14, sendo considerada a ordem de apresentação dos resultados a vida útil do inserto de maneira crescente.

A Figura 14 apresenta a combinação dos resultados obtidos com as 6 configurações de corte aplicadas nos ensaios de usinabilidade, bem como os desvios encontrados através da repetição dos ensaios. Os resultados estão apresentados pela ordem crescente do tempo máximo de usinagem. O maior tempo de usinagem foi obtido com a configuração Vc50fn 0,20 , ou seja, velocidade de corte com $50 \mathrm{~m} / \mathrm{min}$ e avanço de corte com $0,20 \mathrm{~mm} /$ rot. Nesta configuração, foi encontrado a terceira maior taxa de remoção de material, $5 \mathrm{~cm}^{3} / \mathrm{min}$ e uma rugosidade média $\mathrm{R}_{\mathrm{a}}$ de $2,713 \mu \mathrm{m}$ nos 6 ensaios.

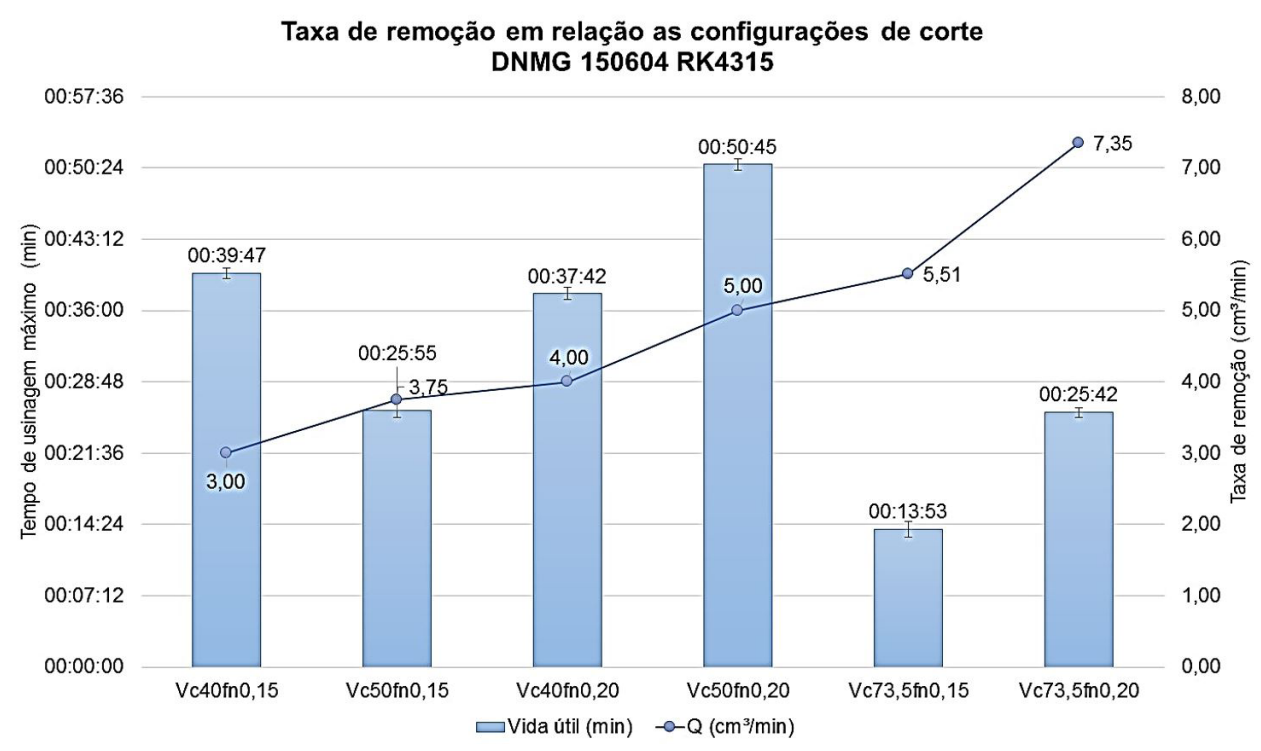

Figura 12. Taxa de remoção (Q) em relação a vida útil do inserto para cada configuração de corte. 


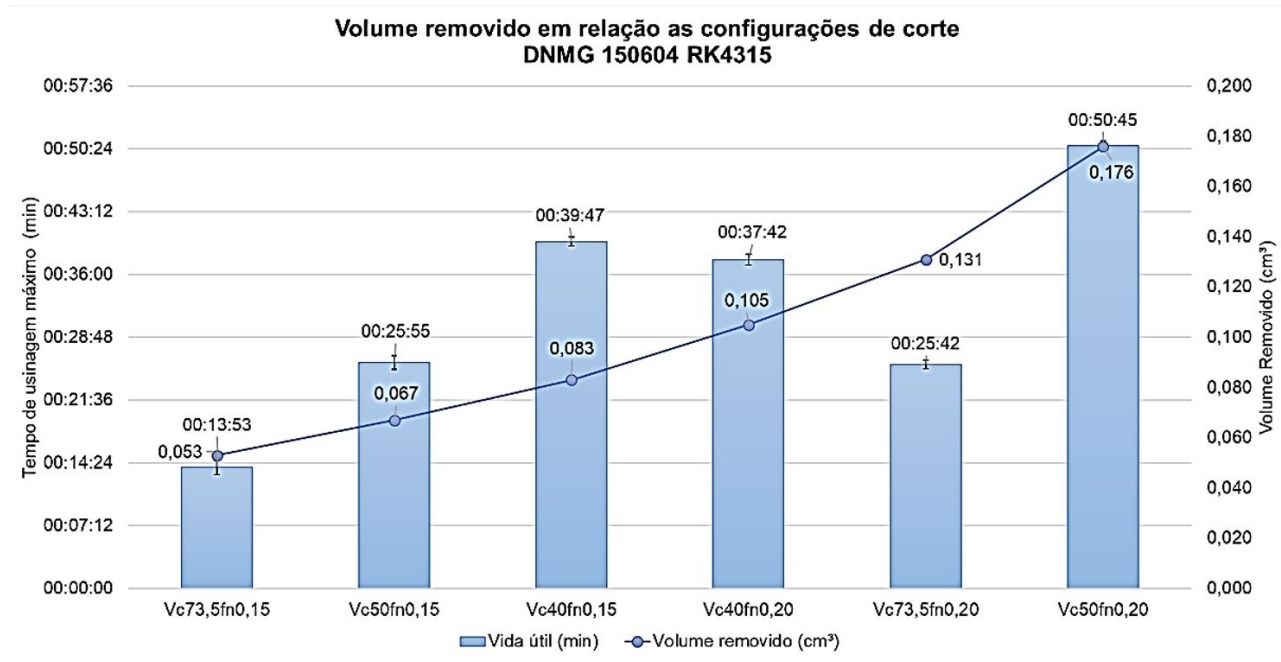

Figura 13. Volume removido em relação a vida útil do inserto para cada configuração de corte.

Taxa de remoção $(Q)$ e Rugosidade média( $R a)$ em relação as config.de corte DNMG 150604 RK4315

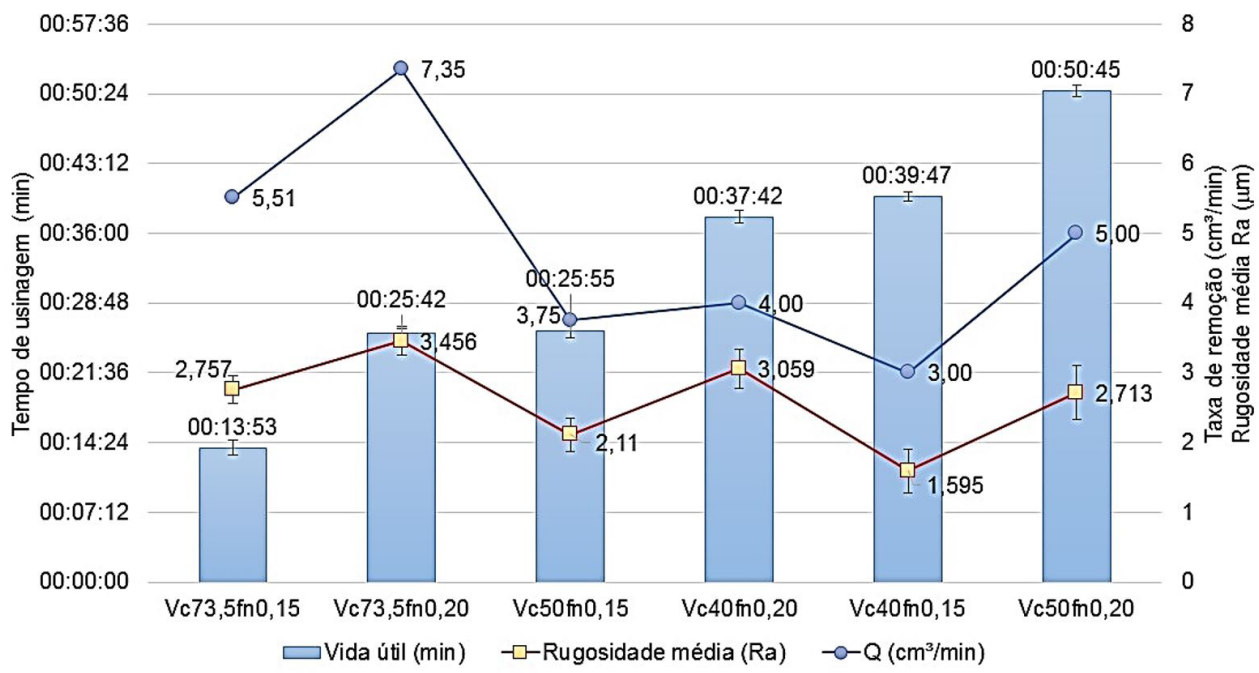

Figura 14. Resumo dos resultados de vida útil, taxa de remoção e rugosidade média obtidos para cada configuração dos ensaios de usinagem.

Tabela 5. Resumo dos parâmetros de corte e resultados para cada configuração dos ensaios de usinagem

\begin{tabular}{|c|c|c|c|c|c|c|c|c|}
\hline \multirow{2}{*}{ Config. } & \multirow{2}{*}{$V_{c}(m / m i n)$} & \multirow{2}{*}{$f_{n}(m m / r o t)$} & \multicolumn{2}{|c|}{ Rugosidade $\mathbf{R}_{\mathrm{a}}(\mu \mathrm{m})$} & \multirow{2}{*}{$\mathrm{Q}\left(\mathrm{cm}^{3} / \mathrm{min}\right)$} & \multicolumn{2}{|c|}{ Tempo de usinagem (min) } & \multirow{2}{*}{$\begin{array}{l}\text { VB máx } \\
\text { (mm) }\end{array}$} \\
\hline & & & Média & DP & & Média & DP & \\
\hline Vc73fn 0,15 & 73,5 & 0,15 & 2,757 & 0,198 & 5,51 & $00: 13: 53$ & 00:00:47 & 0,312 \\
\hline Vc73fn 0,20 & 73,5 & 0,20 & 3,456 & 0,203 & 7,35 & $00: 25: 42$ & 00:00:28 & 0,313 \\
\hline Ve $50 \mathrm{fn} 0,15$ & 50,0 & 0,15 & 2,110 & 0,238 & 3,75 & $00: 25: 55$ & 00:00:45 & 0,301 \\
\hline Vc40fn 0,20 & 40,0 & 0,20 & 3,059 & 0,276 & 4,00 & $00: 37: 42$ & 00:00:38 & 0,303 \\
\hline Vc40fn 0,15 & 40,0 & 0,15 & 1,595 & 0,311 & 3,00 & $00: 39: 47$ & 00:00:31 & 0,363 \\
\hline Vc50fn 0,20 & 50,0 & 0,20 & 2,713 & 0,387 & 5,00 & $00: 50: 45$ & $00: 00: 35$ & 0,300 \\
\hline
\end{tabular}

Nota: DP = Desvio padrão.

\section{Conclusão}

Com os ensaios preliminares realizados a este estudo para definição do melhor inserto de corte, pode-se confirmar que para os 8 insertos testados e suas respectivas configurações de corte, existe um limitante no valor da profundidade de corte $\left(\mathrm{a}_{\mathrm{p}}\right)$, onde para valores superiores a $0,5 \mathrm{~mm}$, o lascamento do material do corpo de prova durante a usinagem de torneamento externo ocorre frequentemente.

Referente as velocidades de corte $\left(\mathrm{V}_{c}\right)$ utilizadas neste estudo, os ensaios foram realizados com valores de 40,50 e 
$73,5 \mathrm{~m} / \mathrm{min}$. Comparados com a velocidade de corte sugerida pelo fabricante para usinagem do material ferro fundido com o inserto DNMG 150604 RK4315 (260 m/min), as velocidades de corte utilizadas foram extremamente menores. Pode-se identificar que o avanço de corte de $0,2 \mathrm{~mm} /$ rot resultou em um maior tempo de usinagem para duas das três velocidades de corte aplicadas, sendo o maior tempo de usinagem encontrado com velocidade de corte de $50 \mathrm{~m} / \mathrm{min}$ e com o avanço anteriormente citado conforme apresentado na Figura 10.

Se a vida útil do inserto fosse a única variável de saída a ser a avaliada neste estudo, poder-se-ia concluir que a configuração Vc50fn0,20 seria a melhor configuração de corte entre as 06 avaliadas, porém outros resultados e variáveis de saída foram avaliadas neste estudo para se obter uma melhor definição.

O parâmetro rugosidade apresentou resultados com pouca variação entre as configurações de corte testadas como pode-se avaliar na Figura 11. Confirmando o que a literatura nos apresenta, a menor rugosidade média $\left(\mathrm{R}_{\mathrm{a}}\right)$ foi encontrada com o menor avanço de corte aplicado. Pode-se perceber uma relação direta entre o aumento da rugosidade média $\left(\mathrm{R}_{\mathrm{a}}\right)$ com o aumento da velocidade de corte e do avanço para os experimentos, exceto para a configuração de corte $\mathrm{Vc} 40 \mathrm{fn} 0,20$. Pela relação lógica apresentada, esta configuração deveria apresentar a segunda menor rugosidade média $\left(\mathrm{R}_{\mathrm{a}}\right)$. O resultado encontrado mostra que para esta configuração a relação anteriormente encontrada não se fez presente, onde ela resultou uma rugosidade considerada como a segunda maior de todas 6 configurações.

Visto que na grande maioria dos projetos de peças fabricadas neste material que solicitam torneamento externo a rugosidade máxima $\left(\mathrm{R}_{\mathrm{a}}\right)$ solicitada é de $6,35 \mu \mathrm{m}$, pode-se afirmar que todas as configurações de corte apresentaram resultados satisfatórios.

Em relação a taxa de remoção $(\mathrm{Q})$, para as configurações e parâmetros de corte aplicadas, a mesma apresentou resultados de 3 a $7,35 \mathrm{~cm}^{3} / \mathrm{min}$. As taxas de remoção foram calculadas em função da velocidade de corte $\left(\mathrm{V}_{\mathrm{c}}\right)$ e o avanço de corte $\left(\mathrm{f}_{\mathrm{n}}\right)$ aplicados a cada configuração conforme apresentados em forma crescente na Figura 12. Para a maior taxa de remoção (Q) encontrada, ou seja, $7,35 \mathrm{~cm}^{3} / \mathrm{min}$, pode-se identificar um dos menores tempos de usinagem do inserto, aproximadamente 25 minutos e 42 segundos. Esta é uma propriedade que está diretamente relacionada com o tempo de usinagem máximo do inserto. Analisando a configuração que apresentou o maior tempo de usinagem, cerca de 50 minutos com 45 segundos, para esta configuração a taxa de remoção (Q) foi de $5 \mathrm{~cm}^{3} / \mathrm{min}$.

Relacionando a configuração da maior taxa de remoção (Q) encontrada (Vc73fn 0,20$)$ com a configuração que teve o maior tempo de usinagem $(\mathrm{Vc} 50 \mathrm{fn} 0,20)$ encontrado, pode-se identificar uma redução de $32 \%$ na taxa de remoção (Q). Realizando a comparação entre as mesmas condições acima citadas, pode-se identificar um aumento de $97 \%$ no tempo de usinagem do inserto para $\mathrm{Vc} 50 \mathrm{fn} 0,20 \mathrm{em}$ relação a Vc73fn0,20, ou seja, quase o dobro.

Após o cálculo das taxas de remoção $(\mathrm{Q})$ uma nova análise pode ser realizada referente ao volume de material removido durante os ensaios. A configuração que apresentou o maior volume de material removido foi a Vc50fn0,20, removendo cerca de $0,176 \mathrm{~cm}^{3}$ durante todo o ensaio. Os resultados para esta e demais configurações estão apresentados na Figura 13.

Portanto, mediante a análise dos resultados apresentados e discutidos neste estudo, a configuração Vc50fn0,20 foi considerada com os melhores parâmetros de corte aplicados ao inserto DNMG 150604 RK4315 no torneamento externo dos corpos de prova fabricados na liga ASTM A518 GR.3, utilizando como velocidade de corte $\left(\mathrm{V}_{\mathrm{c}}\right)$ o valor de $50 \mathrm{~m} / \mathrm{min}$, avanço e corte $\left(f_{n}\right) 0,20 \mathrm{~mm} /$ rot e profundidade de corte $\left(a_{\mathrm{p}}\right)$ de $0,5 \mathrm{~mm}$.

\section{Referências}

1 Jain H, Tripathi J, Bharilya R, Jain S, Kumar A. Optimisation and evaluation of machining parameters for turning operation of Inconel-625. Mater. Today Proc. 2015;2(4-5):2306-2313.

2 ASM International. ASM metals handbook volume 9: metallography and microstructures. Materials Park: ASM International; 1972. p. 255.

3 American Society for Testing and Materials - ASTM. ASTM A518-05: standard specification for corrosion-resistant high-silicon iron castings. West Conshochen: ASTM; 2005. p. 1-5.

4 Altona. Ligas fundidas de ferro silicio. Blumenau; 2002.

5 Smith WF. Principles of materials science and engineering. New York: McGraw-Hill; 1996.

6 Baptista ALB. Aspectos metalúrgicos na avaliação da usinabilidade de aços. Revista Escola de Minas. 2002;55(2):103-109.

7 Kosaraju S, Vijay Kumar M, Sateesh N. Optimization of machining parameter in turning Inconel 625. Materials Today: Proceedings. 2018;5(2):5343-5348.

8 Chandra P, Rao CRP, Kiran R, Kumar VR. Influence of machining parameter on cutting force and surface roughness while turning alloy steel. Materials Today: Proceedings. 2018;5(5):11794-11801. 
Dagostin et al.

9 Kuntoğlu M, Sağlam H. Investigation of progressive tool wear for determining of optimized machining parameters in turning. Measurement. 2019;140:427-436.

10 Associação Brasileira de Normas Técnicas - ABNT. ABNT NBR ISO 3685: tool-life testing with single-point turning tools. Rio de Janeiro: ABNT; 1977. p. 40.

11 Qehaja N, Jakupi K, Bunjaku A, Bruçi M, Osmani H. Effect of machining parameters and machining time on surface roughness in dry turning process. Procedia Engineering. 2015;100:135-140.

12 Vaxevanidis NM, Fountas NA, Koutsomichalis A, Kechagias JD. Experimental investigation of machinability parameters in turning of CuZn39Pb3 brass alloy. Procedia Structural Integrity. 2018;10:333-341.

13 Sandvik. Folheto técnico: pastilha T-max para torneamento dnmg 150604 RK 4315. Sandvik; 2019. p. 4-5.

14 Khan SA, Soo SL, Aspinwall DK, Sage C, Harden P, Fleming M, et al. Tool wear/life evaluation when finish turning Inconel 718 using PCBN tooling. Procedia CIRP. 2012;1(1):283-288. http://dx.doi.org/10.1016/j.procir.2012.04.051.

Recebido em: 21 Dez. 2019

Aceito em: 15 Out. 2020 